\title{
Association of p53 Gene Mutation With Helicobacter pylori Infection in Gastric Cancer Patients and Its Correlation With Clinicopathological and Environmental Factors
}

\author{
M. Mizanur Rahman ${ }^{\mathrm{a}, \mathrm{g}}$, M. Abu Kawsar Sarker ${ }^{\mathrm{b}}$, Md Monowar Hossain ${ }^{\mathrm{c}}$, \\ Mohd. Sahajadul Alam ${ }^{\mathrm{d}}$, Md. Monzurul Islam ${ }^{\mathrm{d}}$, Laila Shirin ${ }^{\mathrm{d}}$, \\ Rokeya Sultana ${ }^{\mathrm{e}}$, Gazi Nurun Nahar Sultana ${ }^{\mathrm{f}}$
}

\begin{abstract}
Background: Gastric cancer is also a leading cancer in Bangladesh like that of the global incidences. It is speculated that environmental, bacterial infection and molecular factors might have been carrying the key role of rising trend of the disease. This study was aimed to investigate the association of mutated $p 53$ gene with of Helicobacter pylori (H. pylori) infection, clinicopathological and some environmental factors of the gastric cancer patients.

Methods: This cross-sectional study was carried out from January 2015 to December 2016 in a specialized cancer hospital of Bangladesh. Patients were selected randomly who were admitted for surgical intervention after diagnosis as adenocarcinoma of the stomach and physically fit for surgery. After admission proper evaluation of the patients was done. Tissue sample from the gastrectomy specimen along with the blood sample was sent to the related laboratories. After DNA extraction for $p 53$, exons 5 and 6 , they were adjusted for proper primer designing. Appropriate sequencing analysis of the result was done. Status of $p 53$ was investigated to see their association with the result of the $H$. pylori, age and sex, tumor status, smoking and extra salt intake of the patients. Result of the study was calculated and analyzed by Chi-square and binomial logistic regression to find the association amongst them.
\end{abstract}

Results: Among the 71 patients, mean age was 52.96 years old, male: female ratio were 48:23, age group above 41 years were $53(74.6 \%)$,

Manuscript submitted January 27, 2019, accepted February 11, 2019

${ }^{a}$ Department of Surgical Oncology, National Institute of Cancer Research and Hospital, Mohakhali, Dhaka, Bangladesh

${ }^{b}$ Aichi Medical College, Uttara, Dhaka, Bangladesh

'Khulna Medical College, Khulna, Dhaka, Bangladesh

dNational Institute of Cancer Research and Hospital, Mohakhali, Dhaka, Bangladesh

${ }^{e}$ Centre for Advanced Research in Sciences (CARS), University of Dhaka, Dhaka, Bangladesh

${ }^{f}$ Genetic Engineering and Biotechnology Research Centre for Advanced Research in Sciences (CARS), University of Dhaka, Dhaka, Bangladesh

'Corresponding Author: M. Mizanur Rahman, Department of Surgical Oncology(ON PRL), National Institute of Cancer Research and Hospital, Mohakhali, Dhaka, Bangladesh. Email: mizannicrh@gmail.com

doi: https://doi.org/10.14740/wjon1087 proliferative and ulceroproliferative group of the tumor dominated (87.3\%). There were 52 cases with (73.2\%) p53 mutation. Among the $51 \mathrm{H}$. pylori positive cases, $41(80 \%)$ had $p 53$ mutation $(\mathrm{P}=0.033)$. Tumor size and lymph node status were found to be associated with the gene mutation $(\mathrm{P}=0.05)$. Age also had strong correlation with the mutation $(\mathrm{P}=0.015)$. Gene mutation was found mostly among the younger ( $\leq 40$ years) group of patients $(94.4 \%)$. Patient with extra salt intake was also found related with the mutation $(\mathrm{P}=0.03)$.

Conclusions: Environmental and genetic factors seem to be risk factors for gastric cancer in Bangladesh. Nationwide anti H. pylori drive and further molecular research could elicit the other risk factors which might help to reduce the gastric cancer incidences in the country after taking appropriate measures.

Keywords: P53 gene; H. pylori; Gastric cancer; Environmental; Clinicopathological; Risk factors

\section{Introduction}

Gastric cancer (GC) is now a leading cause of cancer-related morbidity, causing $9.7 \%$ of all cancer-related mortality around the world [1]. Almost 1 million new cases of stomach cancer were estimated to have occurred in 2012 (952,000 cases, 6.8\% of the total), making it the fifth most common malignancy in the world, after cancers of the lung, breast, colorectum and prostate [2]. More than $70 \%$ of cases $(677,000$ cases) occur in developing countries (456,000 in men, 221,000 in women), and half the world total occurs in Eastern Asia (mainly in China) [2]. Though Bangladesh is lacking a population-based statistics or national cancer registry for cancers; there are very few hospital-based statistics. According to the reports from the national guideline on GC management it is ranking as the fifth most common cancer and the third most common among the males. From the unpublished data across the country from different medical institutions it has been estimated that GC possesses the second position after lung cancer in males [3].

GC may be caused by environmental or lifestyle risks, host genetic polymorphisms, as well as ageing [4]. Many laboratory studies have pointed to roles for carcinogenic substanc- 
es, including amine pyrolysate products and nitrosamines. A probable risk factor for stomach cancer is salt or salty foods, which act synergistically with Helicobacter pylori (H. Pylori) infection in the development of stomach cancer in experimental animals and humans [5]. Some risk factors are described in the literature: smoke is highlighted by the International Agency for Research on Cancer (IARC) [6]; H. pylori also labeled as an important factor for GC [7-9]. So it is now almost a settled issue that interaction among environmental factors, host genetic polymorphism and bacterial virulence collectively influence the clinical outcome of $H$. pylori infections $[10,11]$.

Numerous cytogenetic and molecular genetic studies reached to a common consensus that oncogene over expression, suppressor, mutator, methylator pathway hypotheses, and mismatched DNA repair, but exact molecular mechanisms of GC development remain elusive $[12,13]$.

The TP53 is a tumor suppressor gene encodes a main regulator of cell growth and division. Studies showed that mutations in TP53 are present in a range of $40-70 \%$ of early and advanced GCs, and inactivation of TP53 resulting from loss of heterozygosity (LOH) is found in 60-70\% of intestinal-type GCs. All collectively exponentiate this gene among the most frequently mutated genes in cancers [14]. Still studies are needed to settle the issue regarding the prevalence of TP53 mutations and its relationship to clinicopathological features of GC $[13,15]$. Frequent p53 mutation has been shown in many human cancers; thus, this gene has been associated with carcinogenesis in humans. Gastric mucosal integrity is maintained by apoptosis balanced with cell proliferation. This balance of epithelial cell turnover is altered in the gastric mucosa of patients with GC. With regard to apoptosis, many studies have shown an increased expression and mutation of p53 in $H$. pylori infected gastric mucosa. Therefore, the alteration of the $p 53$ gene is recognized to play a role in gastric carcinogenesis in subjects infected with $H$. pylori $[16,17]$.

In Bangladesh though stomach cancer is a leading cancer and also an important cause for cancer-related death, we have yet to find environmental, molecular and important risk factors. So far, we don't have any in depth or molecular study. Like in other developing countries $H$. pylori infection is also prevalent in Bangladesh. In a recent study on dyspeptic patients $67 \%$ of the subjects showed evidences for $H$. pylori infection in gastric biopsy samples taken by endoscopy [18]. This study was aimed to identify the status of $p 53$ mutation, to find its association with $H$. pylori infection and other clinicopathological and environmental factors in GC patients.

\section{Materials and Methods}

This was a cross-sectional study carried out from January 2015 to December 2016 in the Department of Surgical Oncology, National Institute of Cancer Research and Hospital, Mohakhali, Dhaka, Bangladesh.

\section{Patient selection}

After endoscopic diagnosis of the stomach adenocarcinoma, the patients who were preliminarily selected for surgical candidates were admitted for surgical intervention. Diagnostic workup was completed by routine hematological tests, investigations for general anesthesia, ultrasonography abdomen and in selected cases computed tomography (CT) scan of abdomen. Patient was randomly assigned as every alternate patient was taken into the study when they were finally selected for surgery. Surgeons were unaware of the subjects. Informed consent for surgery and study were taken from each patient. Approval was taken from the Institutions' Ethical Committee. For H. pylori antibody laboratory facilities were taken from the Department of Biochemistry Bangabandhu Sk Mujib Medical University, Dhaka.

\section{Exclusion criteria}

Patients with GCs other than adenocarcinoma, preoperative chemotherapy, radiotherapy, other organ malignancy and those who were unwilling to take part in the study were exclude from the study.

\section{Procedure}

\section{Tissue collection}

Normal and tumor tissues were extracted from the specimen immediately after resection. The specimen surface was washed with normal saline prior to fragment extraction to avoid DNA contamination. Areas of tissue extraction from the specimen were demarcated for routine pathologic examination. Only tissue fragments containing suspected tumor tissue were included for p53 analysis. Normal areas were used as controls.

\section{DNA extraction and optimization}

Tissues were stored at $-80^{\circ} \mathrm{C}$ before DNA purification and extraction. After that tissue was sent to the Laboratory of Genetic Engineering and Biotechnology Department of Centre for Advance Research in Science (CARS), University of Dhaka, under a memorandum of understanding with Surgical Oncology Department for PCR, sequencing and analysis.

In the laboratory tissues were incubated overnight at 55 ${ }^{\circ} \mathrm{C}$ in a buffer containing $100 \mathrm{mM}$ TRIS-HCl (pH 8.5), $5 \mathrm{mM}$ EDTA, $200 \mu \mathrm{g}$ of proteinase $\mathrm{K} / \mathrm{mL}$, and $0.2 \%$ sodium dodecyl sulfate. The samples were cooled to room temperature, and DNA was precipitated with isopropanol and dissolved in $500 \mathrm{~mL}$ of buffer containing $10 \mathrm{mM}$ TRIS (pH 8.2) and $1 \mathrm{mM}$ EDTA.

\section{Primer sequences}

The overlapping primer sequences were used for amplification of p 53 gene. 


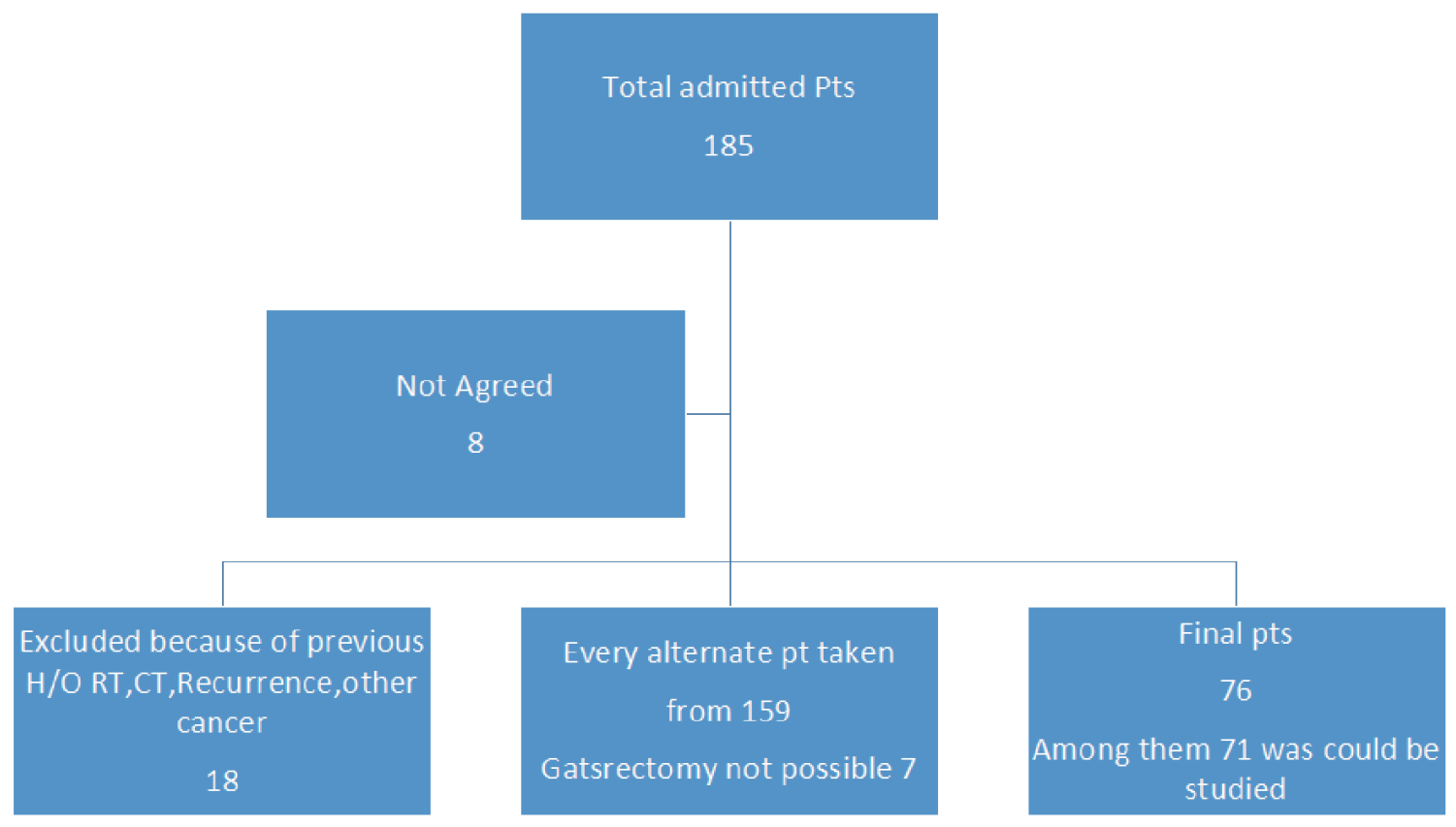

Figure 1. Showing the layout of patients.

\section{PCR amplification}

Primers were designed to amplify the coding region of $p 53$. After PCR, 2\% gel electrophoresis was done along with $1 \mathrm{~kb}$ DNA ladder to check the amplification of distinct PCR products. DNA was amplified in PCR machine in annealing temperature.

\section{Sequencing}

Purified PCR fragments were sequenced directly using a DNA sequencing kit according to Applied Biosystems from USA with Big Dye Terminators on an ABI3700 automated DNA sequencer for $p 53$ after proper primer designing exons 5 and 6 were used. Primer sequence was: $p 53-1$ forward: 5'-ACAAGCAGTCACAGCACATGAC-3' and p53-1 reverse: 5'-TTCAGTAGAGAACGGGGTTTCACC-3'

\section{DNA sequence analysis}

The purified sequencing PCR products were analyzed by electrophoresis in the ABI-Prism 3130 Genetic Analyzer (Applied Biosystems, USA). The sequence patterns were observed and edited using Auto Assembler V 3.0 and BioEdit Sequence Alignment Editor V 7.0.9.0. p53 polymorphisms were compared with the standard genome database of world population.

After finding the genetic changes it was matched with $H$. pylori status, clinicopathological profile like age, sex, tumor characters, types and location and grading of the tumor and some environmental factors like smoking, oral intake of extra salt.

The clinical data were obtained from history, clinical examination and each medical record of the patients. The status of $H$. pylori infection was determined by examining the preoperative sera.

\section{Statistical analyses}

Result of the study was calculated and analyzed by standard statistical method and was presented in forms of tables and figures. Continuous data were expressed as mean \pm standard deviation (SD). For analysis of data Statistical Package for the Social Sciences (SPSS) for Windows (IBM SPSS Statistics for Windows, version 22.0, Armonk, NY: IBM Corp.) software was used. To see the association between categorical variables Chi-squared test (or Fisher's exact test when applicable) was performed. Binomial logistic regression was used to explain the relationship between $p 53$ mutation and H. pylori infection, clinical and environmental factors in GC patients. A value of $\mathrm{P}<0.05$ was considered statistically significant in all analyses.

\section{Results}

\section{Patients}

Finally tissue samples from 71 patients could be examined for genetic tests. Selection of the patients in detail was shown in Figure 1.The mean age of the patients was 52.96 years old with 
Table 1. Factors Related to p53 Mutation

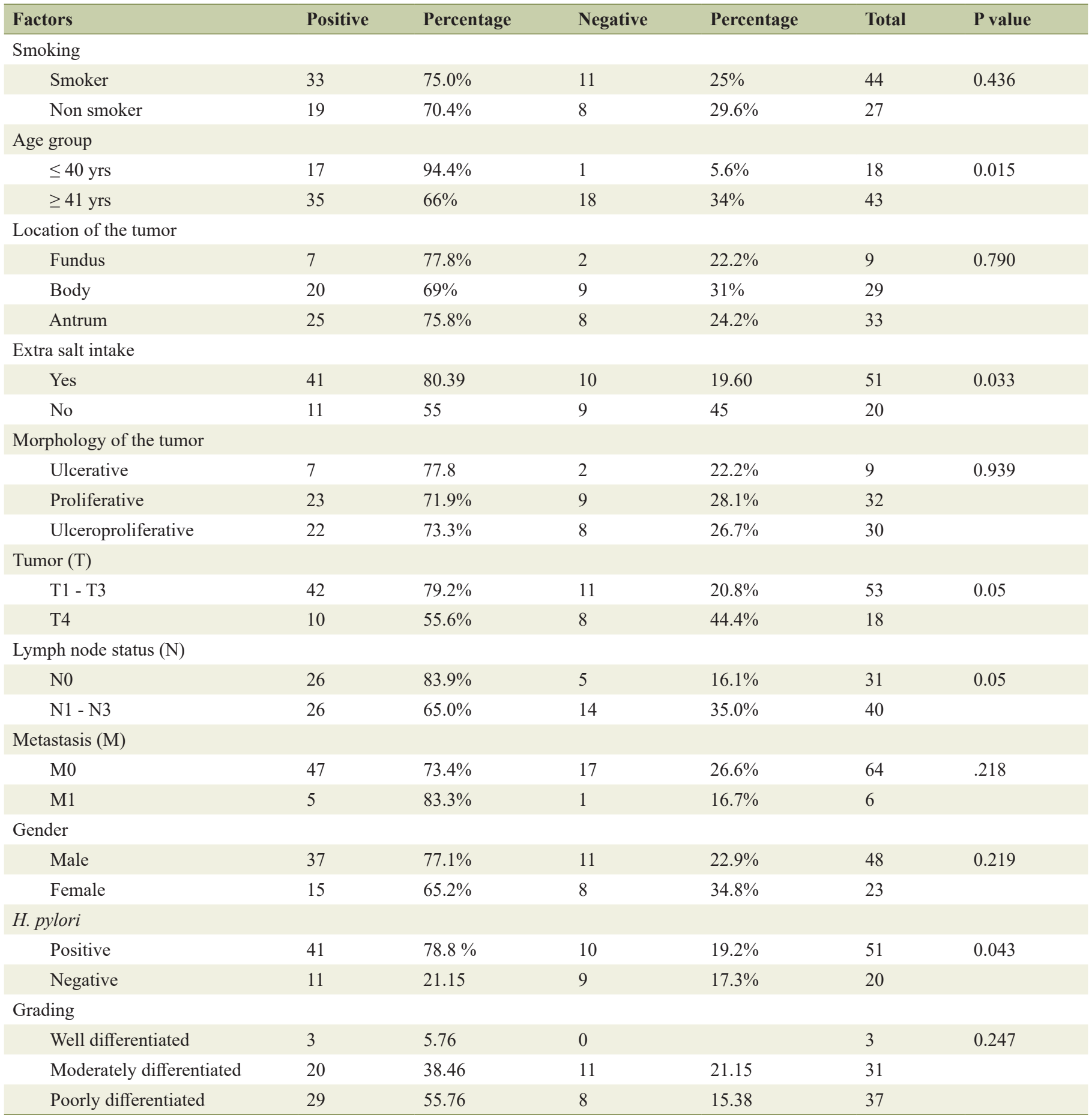

SD of 13.26, ranging from 26 to 87 years; younger group (n $=18$ ) was categorized as 40 years or below; male: female ratio was $48: 23$. As generally in the public hospital people from a lower socioeconomic condition take their services, we can assume that majority are from poorer section of the society. Tumor staging T1-T3, and grading G1, G2, and G3 was shown in Table 1. Morphology was categorized as proliferative and ulceroproliferative ones, with the number is $62(87.3 \%) . H$. pylori antibody analysis showed that among the 51 positive cases, $41(80 \%)$ had mutated $p 53$ gene. The rest 11 cases with mutation were found among the $20 \mathrm{H}$. pylori non-infected cases. Chi-square test and Fisher's exact test showed that $H$. pylori infection has got strong association with the mutation $(\mathrm{P}=0.033)$. The tumor was described as location, morphology, 
Table 2. Logistic Regression Analysis of $H$. pylori and p53 Mutation (Dependent Variable: $p 53$, Sample Size $=71$ )

\begin{tabular}{llll} 
& & \multicolumn{1}{c}{ Model summary } & Nagelkerke R Square \\
\hline Step & $\mathbf{- 2}$ Log likelihood & Cox \& Snell R Square & 0.456 \\
\hline 1 & $55.798^{\text {a }}$ & 0.313 & \\
\hline
\end{tabular}

aEstimation terminated at iteration number 6 because parameter estimates changed by less than 0.001 .

and size. It was seen that to find correlation with location of the tumor (cardia, midbody and antral), majority $(>75 \%)$ of the lesion found in antral part (found no significant correlation with mutation), morphology of the tumor which was categorized as ulcerative, proliferative and ulceroproliferative didn't have any significant correlation with the mutation $(P=0.939)$, but the size of the tumor and lymph node involvement (N1 - N3) have significant correlation with the mutation $(\mathrm{P}=0.05)$. Other factors like gender, smoking carried no impact on the mutation status. But extra salt intake in the regular diet had strong correlation with the mutation. Considering the age group, 18 patients were at or below 40 years of age, 17 of them had $p 53$ mutation $(\mathrm{P}=0.015)$, which reflects a very strong association with age. The logistic regression was performed to ascertain the effects of age, gender, tumor status (T), grading, node status, smoking, and extra salt intake. The model explained $66.0 \%$ (Nagelkerke $\mathrm{R}^{2}$ ) of the variance gene mutation of GC and correctly classified $87.0 \%$ of cases.

The Wald test ("Wald" column) is used to determine statistical significance for each of the independent variables. The statistical significance of the test is found in the "Sig" column. From these results we can see that morphology $(2)(\mathrm{P}=0.037)$, Stage T (1) $(\mathrm{P}=0.004), H$. pylori $(1)(\mathrm{P}=0.012)$, grading $(\mathrm{P}=$ $0.031)$, grading $(2)(\mathrm{P}=0.008)$ and age group $(\mathrm{P}=0.006)$ added significantly to the model/prediction, but other independent variables did not add significantly to the model.

H. pylori-infected cases, younger patients, T4 diseases, body tumors had more chances of association with p53 mutation, which was shown in Tables 2-5.

Table 3. Variables in the Equation

\begin{tabular}{lllllll}
\hline & Coefficient & SE & Wald & DF & Sig & Exp(B) \\
\hline Smoking & -0.235 & 0.883 & 0.071 & 1 & 0.790 & 0.790 \\
Location & -0.210 & 0.508 & 0.171 & 1 & 0.679 & 0.810 \\
Extra salt & 1.149 & 0.845 & 1.848 & 1 & 0.174 & 3.155 \\
Morphology & -0.257 & 0.526 & 0.238 & 1 & 0.625 & 0.773 \\
Stage T & 1.822 & 0.863 & 4.454 & 1 & 0.035 & 6.184 \\
Stage N & 1.150 & 0.872 & 1.738 & 1 & 0.187 & 3.159 \\
Stage M & -0.610 & 1.663 & 0.135 & 1 & 0.714 & 0.543 \\
Sex & 0.616 & 0.807 & 0.583 & 1 & 0.445 & 1.851 \\
H. pylori & 2.060 & 0.775 & 7.062 & 1 & 0.008 & 7.848 \\
Grading & -0.837 & 0.609 & 1.890 & 1 & 0.169 & 0.433 \\
Age group & 2.693 & 1.330 & 4.103 & 1 & 0.043 & 14.780 \\
Constant & -11.258 & 4.223 & 7.107 & 1 & 0.008 & 0.000 \\
\hline
\end{tabular}

SE: standard error; DF: degree of freedom; Sig: significance level; Exp (B): exponentiation of the $B$ coefficient, which is an odds ratio.

\section{Discussion}

In this study tissue sample from gastrectomy specimen was taken for $p 53$ gene mutation, blood sample was taken for investigation about $H$. pylori status. Samples were sent to two different laboratories. Finally results of the two tests were matched to find the linkages between $p 53$ gene mutation with H. pylori positivity. We also investigated the correlation of p53 mutation with age, sex, tumor profile and daily habits like smoking and extra salt intake in the daily diets.

\section{H. pylori infection and p53 mutation}

On gene analysis it was seen that among the $H$. pylori infected cases over $80 \%$ have alteration of $p 53$ in the tested gene in the current series, despite of using only exons 5 and 6. Chisquare and regression analysis shows that they have strong and significant association. In Bangladesh there was no previous study in this field. Around the globe there are different studies covering this area. It has been suggested that $H$. pylori can initiate GC through $p 53$ tumor suppressor mutation [19]. The $p 53$ abnormalities have been assessed in several studies of GC associated with $H$. pylori infection [20,21], but controversy still remains. Still it has been suggested that $H$. pylori initiates GC through $p 53$ tumor suppressor mutation [19]. Other study concludes that $H$. pylori infection affects $p 53$ expression in tumor tissue of GC sections. The average $p 53$ expression was significantly higher in tumor than in normal tissues. Overall, the detection of $p 53$ in tumor tissue of resected GC sections provided additional supportive evidence for the effect of $H$. pylori on its expression $[22,23]$ even in the form of chronic gastritis which was labeled as preneoplastic to neoplastic changes [22, 24].

\section{Age and sex}

On analysis of the altered p53 gene in this study, it was found that it had a strong correlation with age of the patients. The age group of this study was categorized as 40 years (younger) or below and 41 years or above; nearly all of the younger patients had gene mutation. It was a common fact that ageing and carcinogenesis runs together. Among many cancers it is observed that gastric and colorectal ones also occur more often in the elderly. Studies show that GC rarely occurs before the age of 40 years, with aging its incidence increases, and getting the peak in the seventh decade $[25,26]$. Reasons may be that longterm exposure of cancer-causing agents has been offered for the age-dependent rise in malignancies [27]. Carcinogenesis, which is a multistep process, results from the accumulation of 
Table 4. Contribution of Each Independent Variable to the Model and Its Statistical Significance

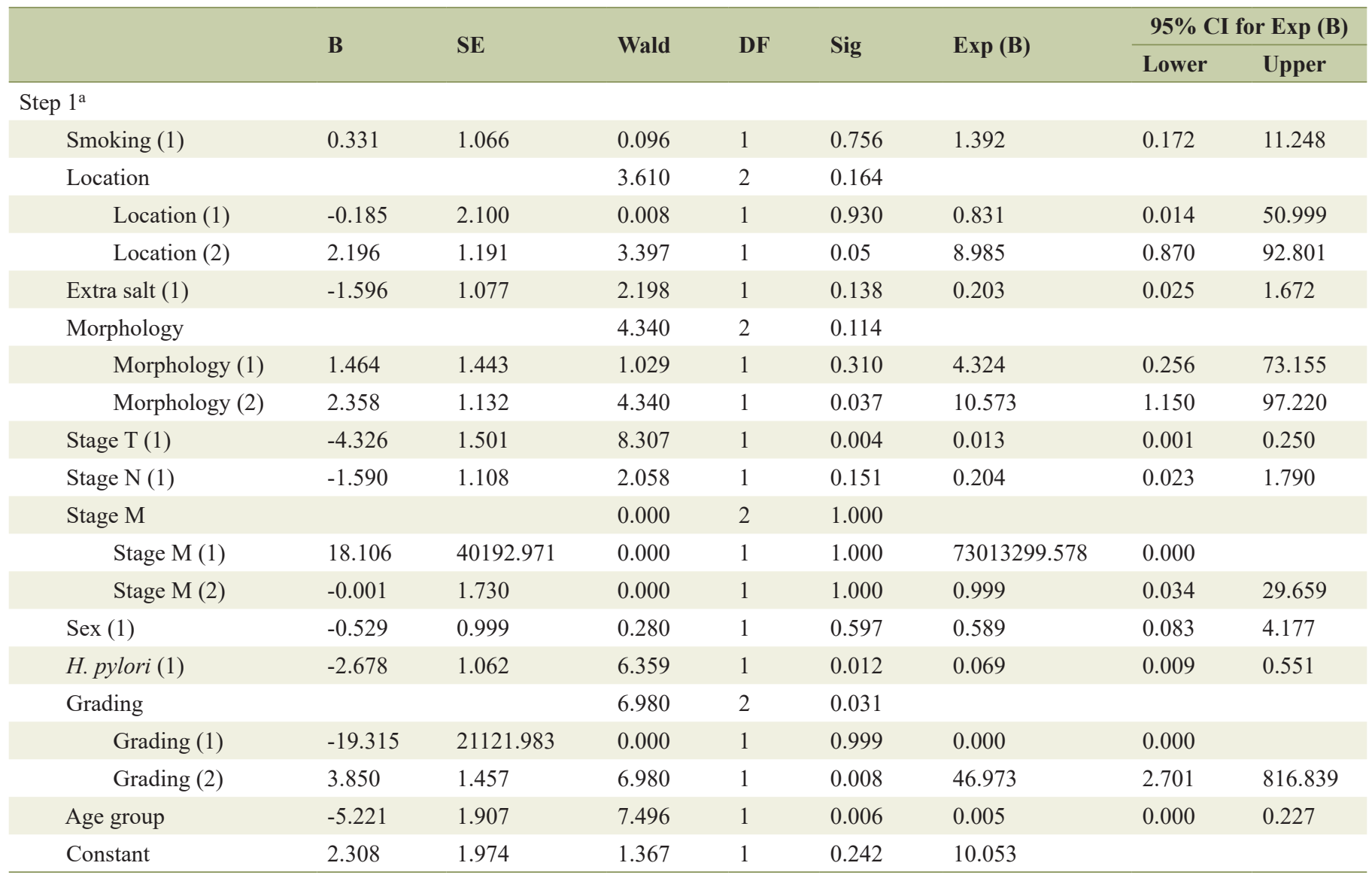

aVariable (s) entered on step 1: smoking, location, extra salt, morphology, stage T, stage N, stage M, sex, H. pylori, grading, and age. SE: standard error; DF: degree of freedom; Sig: significance level; $\operatorname{Exp}(B)$ : exponentiation of the $B$ coefficient, which is an odds ratio.

mutations during progression from normal epithelium to carcinoma [28]. Their view expressed that in humans, the incidence of mutations of several tumor suppressor genes, specifically $A P C, D C C$, and $p 53$ in the gastric mucosa, is higher in older subjects [25]. But other study found $p 53$ mutation in younger subjects of proximal stomach cancers [29]. In this study it is seen that younger patients are more prone to have gene mutation. Regarding to gender distribution, males are prone to develop GC, which matches with this study $[25,26]$; but it is not found to have significant mutation in the current study.

\section{Tumor profile}

In this study, we tried to find correlation of $p 53$ mutation with the different domains of the tumor factor like morphology, lo-

Table 5. Odd Ratio of p53 Mutation in H. pylori-Infected Patients cation, extension and grading. Though most of the tumors are located within mid body and antrum it does not have any significant correlation. On the other hand extension of the tumor, lymph node involvement had significant correlation with the genetic mutation. Though there is limited study on the clinical relevance with gene alteration, it has been shown in different previous studies that it is associated with advanced stage, higher grade $[30,31]$, and some study had found negative association with lymph node status, grading and metastasis [29].

\section{Environmental factors}

The first is extra salt intake. It has been seen that in some areas of Bangladesh people are prone to have more GC in their vicinity. On enquiry and also in the series some of the patients

\begin{tabular}{|c|c|c|c|c|}
\hline & \multicolumn{2}{|c|}{ H. pylori } & \multirow{2}{*}{ Odd ratio } & \multirow{2}{*}{ Interpretation } \\
\hline & Positive & Negative & & \\
\hline p53 positive & 41 & 11 & 3.35 & $\begin{array}{l}\text { People having positive } H \text {. pylori have } 3.35 \text { times the chance of } p 53 \\
\text { mutation compared to people having negative } H \text {. pylori. }\end{array}$ \\
\hline
\end{tabular}


have routine habit to consume extra salt in their daily meals; on analysis it was found that it has strong correlation with $p 53$ mutation. A prospective study from a Japanese population suggests that high dietary salt intake ( $>10 \mathrm{~g}$ per day) is a significant risk factor for $\mathrm{GC}$, and this association was found to be stronger in the presence of $H$. pylori infection with atrophic gastritis [32, 33].

Smoking is also a common habit among the male in this part of the world. Since GC is a male dominant disease it is likely that smoking may be a predisposing risk factor of the disease. Though there were a good number of smoker patients (63.4\%), 75\% had p53 mutation in our series; it doesn't have significant correlation on regression analysis and Chi-square test. Although the role of smoking in causing several other cancers has long been established, it was not until 2002 that the International Agency for Research on Cancer concluded that there was "sufficient" evidence of causality between smoking and GC [34]. In a large population-based study in Europe (EPIC), $17.6 \%$ of GC cases were related to smoking [35]. Though the exact mechanisms are unclear, studies predicted that oxygen radicals and increased apoptosis associated with smoking induces precancerous changes in the gastric epithelium, further promoting the progression of carcinogenesis [36]. There is limited study on association of $p 53$ mutation with smoking. But there are few studies on $p 53$ and cancer. In a larger Saudi study they found no association of $p 53$ mutation among the smokers [37]. A statistically significant association was found between $p 53$ mutations and exposure to tobacco smoke $(\mathrm{P}=0.001)$, which was the only variable significantly associated with $p 53$ mutations in a multivariate model [38].

In Bangladesh, GC incidence is in rising trend. Regarding $H$. pylori infection, different studies directed that in the last 20 years infection is in down trend [39]. In a case control study [40] to see relationship of GC with $H$. pylori infection, it is well established that there is also a close association of H. pylori infection with GC. We have yet to find any molecular study. Within this limited facility we could finally explore the status of p53 alteration which is remarkably present in our patients and have strong association with $H$. pylori infection.

\section{Conclusions}

As Bangladesh still being a member of the low economic country in the globe, it has to bear big burden and carry devastating tales of the GC patients. The disease has a higher mortality and poor patients have to bear intolerable sufferings in the terminal stages when the standard therapeutic measures cannot be offered. On the other hand it is established that the disease is an inflammation-associated cancer, and in addition to the inflammation, the $H$. pylori organism itself can directly cause genetic instability, which is also influenced by environmental factors and some host factors. The current study found genetic alteration in $H$. pylori-infected patients which is synergistically affected by clinical and environmental factors. Cure of $H$. pylori prior to development of different steps of carcinogenesis will essentially prevent the development of GC. It seems to be the fact that the status of $p 53$ in the tumor cannot inform about the stage of the tumor but assessing $p 53$ status may be beneficial in early detection and monitoring of tumor relapse, by detecting p53 antibodies and mutant p53 DNA. Furthermore, analysis of $p 53$ status can serve as a tool in the prediction of effective therapeutic regimens, whereas $p 53$ itself particularly mutant $p 53$, may represent targets for cancer therapy [41]. Additional molecular studies in a larger scale to delineate exact molecular mechanisms linking the relationship with environmental, demographic and host factors are needed. A large scale nationwide anti- $H$. pylori measures in the community particularly in the low income section of people may bring a drastic declining change for the future GC incidences.

\section{Acknowledgments}

Many thanks to Mr. Shamsul Alam Akhond, the senior counsellor of Bangladesh Institute of Management, Dhanmondi, Dhaka, who has kindly facilitated the statistical analysis.

\section{Funding Disclosure}

This study was supported by the Ministry of Education, Government of Bangladesh which helped to carry out the laboratory expenses.

\section{Author Contributions}

M Mizanur Rahman designed and initiated the study, made a team, collected the literature, and regularly monitored during patient recruitment, sample collection, managed the fund, regularly monitored the works and played role for data compilation and analysis of the result and final drafting of the manuscript. M. Abu Kawser Sarker, Md Monoar Hossain, Md Monzurul Islam and Shajadul Alam were responsible for patient selection, scrutiny, sample collection from the operation theatre and all steps up to the laboratories, data collection and compilation. Laila shirin was assigned for data analysis and drafting. Rokeya Sultana and Gazi Nurunnahar were responsible for dealing with the work of genetic part, primer designing, PCR amplification, sequencing and final analysis. It is stated that all authors have read and approved the manuscript.

\section{Conflict of Interest}

The authors declare that they have no conflict of interests. To

\section{References}

1. Ferro A, Peleteiro B, Malvezzi M, Bosetti C, Bertuccio P, Levi F, Negri E, et al. Worldwide trends in gastric cancer mortality (1980-2011), with predictions to 2015, and incidence by subtype. Eur J Cancer. 2014;50(7):1330-1344.

2. http://globocan.iarc.fr/old/FactSheets/cancers/stomachnew.asp accessed on 12.08.2017. 
3. Gastric Cancer Management. National Guideline of Bangladesh. 2014.

4. World Cancer Research Fund/American Institute for Cancer Research.Food, Nutrition and the prevention of cancer: a global perspective. Washington, DC: World Cancer Research Fund/American Institute for Cancer Research, 1997.

5. Nozaki K, Shimizu N, Inada K, Tsukamoto T, Inoue M, Kumagai T, Sugiyama A, et al. Synergistic promoting effects of Helicobacter pylori infection and high-salt diet on gastric carcinogenesis in Mongolian gerbils. Jpn J Cancer Res. 2002;93(10):1083-1089.

6. IARC. Monographs on the evaluation of carcinogenic risks to humans. Tobacco Smoke and Involuntary Smoking. Vol. 83. Lyon: IARC, 2004.

7. Uemura N, Okamoto S, Yamamoto S, Matsumura N, Yamaguchi S, Yamakido M, Taniyama K, et al. Helicobacter pylori infection and the development of gastric cancer. N Engl J Med. 2001;345(11):784-789.

8. Brenner H, Arndt V, Stegmaier C, Ziegler H, Rothenbacher D. Is Helicobacter pylori infection a necessary condition for noncardia gastric cancer? Am J Epidemiol. 2004;159(3):252-258.

9. Tokudome S, Samsuria Soeripto WD, Triningsih FX, Suzuki S, Hosono A, Triono T, Sarjadi IW, et al. Helicobacter pylori infection appears essential for stomach carcinogenesis: observations in Semarang, Indonesia. Cancer Sci. 2005;96(12):873-875.

10. Blaser MJ, Berg DE. Helicobacter pylori genetic diversity and risk of human disease. J Clin Invest. 2001;107(7):767773.

11. Khatoon J, Rai RP, Prasad KN. Role of Helicobacter pylori in gastric cancer: Updates. World J Gastrointest Oncol. 2016;8(2):147-158.

12. Resende C, Ristimaki A, Machado JC. Genetic and epigenetic alteration in gastric carcinogenesis. Helicobacter. 2010;15(Suppl 1):34-39.

13. Panani AD. Cytogenetic and molecular aspects of gastric cancer: clinical implications. Cancer Lett. 2008;266(2):99-115.

14. Hamilton JP, Meltzer SJ. A review of the genomics of gastric cancer. Clin Gastroenterol Hepatol. 2006;4(4):416425.

15. Hudler P, Vogelsang M, Komel R. Genetic Instability in Gastric Cancer. Available on www.intechopen.com accessed on 12.07.2107.

16. Nardone G, Staibano S, Rocco A, Mezza E, D'Armiento F P, Insabato L, Coppola A, et al. Effect of Helicobacter pylori infection and its eradication on cell proliferation, DNA status, and oncogene expression in patients with chronic gastritis. Gut. 1999;44(6):789-799.

17. Sawaya M, Yoshimura T, Shimoyama T, Munakata A, Fukuda S. Difference of p53AIP1 mRNA expression in gastric mucosa between patients with gastric cancer and chronic gastritis infected with Helicobacter pylori. J Clin Gastroenterol. 2008;42(4):351-355.

18. Habib AM, Alam MJ, Rudra B, Quader MA, Al-Forkan M. Analysis of Helicobacter pylori Prevalence in Chittagong, Bangladesh, Based on PCR and CLO Test. Mi- crobiol Insights. 2016;9:47-50.

19. Lan J, Xiong YY, Lin YX, Wang BC, Gong LL, Xu HS, Guo GS. Helicobacter pylori infection generated gastric cancer through p53-Rb tumor-suppressor system mutation and telomerase reactivation. World J Gastroenterol. 2003;9(1):54-58.

20. Li JH, Shi XZ, Lv S, Liu M, Xu GW. Effect of Helicobacter pylori infection on p53 expression of gastric mucosa and adenocarcinoma with microsatellite instability. World J Gastroenterol. 2005;11(28):4363-4366.

21. Andre AR, Ferreira MV, Mota RM, Ferrasi AC, Pardini MI, Rabenhorst SH. Gastric adenocarcinoma and Helicobacter pylori: correlation with p53 mutation and p27 immunoexpression. Cancer Epidemiol. 2010;34(5):618-625.

22. Salih BA, Gucin Z, Bayyurt N. A study on the effect of Helicobacter pylori infection on p53 expression in gastric cancer and gastritis tissues. J Infect Dev Ctries. 2013;7(9):651-657.

23. Unger Z, Molnar B, Pronai L, Szaleczky E, Zagoni T, Tulassay Z. Mutant p53 expression and apoptotic activity of Helicobacter pylori positive and negative gastritis in correlation with the presence of intestinal metaplasia. Eur J Gastroenterol Hepatol. 2003;15(4):389-393.

24. Jorge O, Cuello Carrion FD, Jorge A, Ciocca DR. Helicobacter pylori infection affects the expression of PCNA, p53, c-erbB-2 and Bcl-2 in the human gastric mucosa. Rev Esp Enferm Dig. 2003;95(2):97-104, 189-196.

25. Moragoda L, Jaszewski R, Kulkarni P, Majumdar AP. Age-associated loss of heterozygosity of tumor suppressor genes in the gastric mucosa of humans. Am J Physiol Gastrointest Liver Physiol. 2002;282(6):G932-936.

26. Rugge M, Fassan M, Graham DY. Epidemiology of Gastric cancer. Gastric Cancer.

27. Dilman VM. Ageing, metabolic immunodepression and carcinogenesis. Mech Ageing Dev. 1978;8(3):153-173.

28. Fearon ER. Genetic alterations underlying colorectal tumorigenesis. Cancer Surv. 1992;12:119-136.

29. Ireland AP, Shibata DK, Chandrasoma P, Lord RV, Peters JH, DeMeester TR. Clinical significance of p53 mutations in adenocarcinoma of the esophagus and cardia. Ann Surg. 2000;231(2):179-187.

30. Wu MS, Shun CT, Wang HP, Sheu JC, Lee WJ, Wang TH, Lin JT. Genetic alterations in gastric cancer: relation to histological subtypes, tumor stage, and Helicobacter pylori infection. Gastroenterology. 1997;112(5):1457-1465.

31. Waraya M, Yamashita K, Ema A, Katada N, Kikuchi S, Watanabe M. Exclusive Association of p53 mutation with super-high methylation of tumor suppressor genes in the p53 pathway in a unique gastric cancer phenotype. PLoS One. 2015;10(10):e0139902.

32. Shikata K, Kiyohara Y, Kubo M, Yonemoto K, Ninomiya T, Shirota T, Tanizaki Y, et al. A prospective study of dietary salt intake and gastric cancer incidence in a defined Japanese population: the Hisayama study. Int J Cancer. 2006;119(1):196-201.

33. Lazarevic K, Nagorni A, Rancic N, Milutinovic S, Stosic L, Ilijev I. Dietary factors and gastric cancer risk: hospital-based case control study. J BUON. 2010;15(1):89-93.

34. Humans IWGotEoCRt. IARC monographs on the evalua- 
tion of carcinogenic risks to humans. Ingested nitrate and nitrite, and cyanobacterial peptide toxins. IARC Monogr Eval Carcinog Risks Hum. 2010;94:v-vii, 1-412.

35. Gonzalez CA, Pera G, Agudo A, Palli D, Krogh V, Vineis $\mathrm{P}$, Tumino R, et al. Smoking and the risk of gastric cancer in the European Prospective Investigation Into Cancer and Nutrition (EPIC). Int J Cancer. 2003;107(4):629-634.

36. Wang H, Ma L, Li Y, Cho CH. Exposure to cigarette smoke increases apoptosis in the rat gastric mucosa through a reactive oxygen species-mediated and p53-independent pathway. Free Radic Biol Med. 2000;28(7):1125-1131.

37. Alshammari FD. Molecular screening for p53 mutations among tobacco smokers in a survey of awareness of links between tobacco, alcohol use and cancer in Saudi Arabia. Asian Pac J Cancer Prev. 2015;16(16):6845-6849.

38. Ronchetti D, Neglia CB, Cesana BM, Carboni N, Neri
A, Pruneri G, Pignataro L. Association between p53 gene mutations and tobacco and alcohol exposure in laryngeal squamous cell carcinoma. Arch Otolaryngol Head Neck Surg. 2004;130(3):303-306.

39. Ahmad MM, Rahman M, Rumi AK, Islam S, Huq F, Chowdhury MF, Jinnah F, et al. Prevalence of Helicobacter pylori in asymptomatic population - a pilot serological study in Bangladesh. J Epidemiol. 1997;7(4):251-254.

40. Sarker KK, Kabir MJ, Bhuyian A, Alam MS, Chowdhury FR, Ahad MA, Rahman MA, et al. H. pylori infection and gastric cancer in Bangladesh: a case-control study. Int J Surg Oncol (N Y). 2017;2(10):e44.

41. Rivlin N, Brosh R, Oren M, Rotter V. Mutations in the p53 tumor suppressor gene: important milestones at the various steps of tumorigenesis. Genes Cancer. 2011;2(4):466474. 